\title{
Nutritional Status of Under Five Year Children and Factors Associated in Kapilvastu District, Nepal
}

\author{
Tulsi Ram Bhandari* and Muniraj Chhetri \\ Department of Public Health, Faculty of Science and Technology, Pokhara University, Kaski, Nepal
}

Received: October 25, 2013; Accepted: December 19, 2013; Published: December 30, 2013

*Corresponding author: Tulsi Ram Bhandari, Department of Public Health, Faculty of Science and Technology, Pokhara University, Kaski, Nepal; Tel: 00977975109863; Email: tulsib2004@gmail.com

\begin{abstract}
Introduction: Nutritional status of children is a proxy indicator for assessing the entire population health status and one of the major predictors of child survival. Despite the various efforts, malnutrition among children is remaining as a major public health problem in Nepal. This study was conducted to assess the nutritional status of under-five year children and to find out the factors associated with childhood malnutrition.
\end{abstract}

Methods: For assessing the nutritional status of under-five children and factors associated a cross-sectional study was conducted in Kapilvastu district, Nepal. District was selected purposively and out of 76 village development committees (VDCs) of the district 30 VDCs were selected by applying simple random method. Total 450 children i.e. 15 children from each VDC were chosen conveniently. Statistical Package for the Social Sciences (SPSS) 16 version and World Health Organization (WHO) Anthro 3.2.2 version were used for analyzing the data.

Results: Better socio-economic status, mother's age 20-35 years, birth order up to second, gap more than two year between two pregnancies, recommended exclusive breast feeding, early recommended supplementary foods, complete immunization and timely care seeking had positive effect on children health, which were also statistically significant. Considering the weight-for-height, height-for-age, BMI-for-age and MUAC-for-age; $5 \%$ to $60 \%$ children were below -2SD (standard deviation) and nearly one-fourth below -3 SD.

Conclusion: In Kapilvastu more than $60 \%$ children had any kind of malnutrition. Out of them nearly one-fourth children were in critical condition (below -3SD) and they need immediate intervention.

Keywords: Factors associated; Nutritional status; Under five year children

\section{Introduction}

Malnutrition in children and women is a major publichealth problem in most of the developing countries and Protein Energy Malnutrition (PEM) is more common among underfive year children. Childhood malnutrition is major underlying cause $(>50 \%)$ of the under 5 year children deaths. Every year 7.6 million children die such preventable malnutrition and its related causes. Similarly, next prevalent cause of infant and child mortality is low birth weight which leads to the intergeneration cycle of malnutrition especially in female $[1,2]$.

Socio-cultural practices such as less consideration for supplementary child feedings, late weaning and poverty are major causal factors of malnutrition among under-five year children [3]. Child health nutritional indicators are used to assess the quality of available health services as well as the general health condition of the entire population. Similarly, childhood nutritional status also determines the health and disease conditions of children in the future life.

\begin{tabular}{|l|c|c|c|c|c|}
\hline Indicators & Mean & Mode & $\begin{array}{c}\text { Standard } \\
\text { deviation }\end{array}$ & Range & Number \\
\hline $\begin{array}{l}\text { Number of family } \\
\text { members }\end{array}$ & 6.38 & 4 & 2.48 & 2 to 13 & 450 \\
\hline $\begin{array}{l}\text { Age of mother at first } \\
\text { pregnancy }\end{array}$ & 18.73 & 17 & 1.72 & $\begin{array}{c}16 \text { to } \\
24\end{array}$ & 450 \\
\hline Number of children & 2.39 & 2 & 1.39 & 1 to 8 & 450 \\
\hline Birth order of child & 2.40 & 2 & 1.43 & 1 to 8 & 450 \\
\hline Birth spacing in year & 2.42 & 2 & 0.84 & 1 to 5 & 321 \\
\hline
\end{tabular}

Table 1: Demographic and maternal-child health information.

Table 1 shows maternal-child health information where nearly $87 \%$ of mothers were below 20 years old at their first pregnancy and mean and mode age of the mother at first pregnancy were 18.73 and 19 years. Birth orders of the children was 1 to 8 and mean, mode and standard deviation of the birth order were respectively 2.38, 2 and 1.4. Age difference between the youngest child and previous child was one to five years. Mean, mode and standard deviation of birth spacing were 2.39, 2 and 0.84 year correspondingly.

$53.03 \%$ women practiced exclusive breast feeding up to 5 month and mean, mode and standard deviation of the exclusive breast feeding were respectively 4.62, 5 and 0.81 months. No sooner families started the supplementary food, most of the families did not prepare separate nutritional foods for their children and they gave to children whatever was prepared for the entire family. More than $93 \%$ children were immunized completely in the study area. Study further shows that those children who suffered from malnutrition, they also had higher episodes of diarrhea and acute respiratory tract infections as compared to nonmalnourished children within a year.

Anthropometric measurements i.e. weight-for-height, weight-for-age, height-for-age, BMI-for-age and MUAC-for-age were used for assessing the current nutritional status of children. 
Nepal National Census 2001 pointed that the 0-4 year children population was $13 \%$ of the total population. Likewise, infant mortality rate more than 60 per thousand, literacy rate 41.8 percent, and life expectancy at birth 62.5 years were there $[4,5]$. A large number of cases moderate to severe acute PEM and micronutrient deficiencies in Nepal and malnutrition status as a serious health problem for child survival and their growth and development [6].

Childhood malnutrition existed in various degrees in different ecological zones and developmental regions of Nepal. Low birth weight, PEM and micronutrient deficiencies were most common form of nutritional problems among under five year children in plain districts of Nepal. Despite the availability of nutritional products and good climatic opportunities for agricultural products, transportation facilities, easy access to health services most of the children suffered from malnutrition due to behavioral and socio-cultural practices in these districts $[5,7]$.

Based on the Human Development Index (HDI) Kapilvastu district was found below the average level of other plain districts of the western development region of Nepal $[4,5]$. Considering the low progress of health and socio-economic indicators, this district was selected for the study. The study was focused to assess the nutritional status of under-five year children and to find out the factors associated with childhood malnutrition.

\section{Methods}

A descriptive cross-sectional study was conducted from
January to May 2010 in Kapilvastu district of Nepal. Ethical approval was taken from Institutional Research Board of Faculty of Science and Technology, Pokhara University Nepal. Kapilvastu district was selected purposively by considering the low socioeconomic and health indicators out of the plain districts of western development region of Nepal. This district comprises of 76 Village Development Committees (VDCs), out of 76 VDCs 30 VDCs were selected by using simple random sampling method. For collecting required information, 15 pairs of under five year children and their mother/care taker were measured and interviewed from each VDC conveniently. For obtaining the required information and anthropometric measurements enumerators went through to VDCs and interviewed with either mother or caretaker of child and took measurements of children. They followed random direction until meeting the required number of mother and child pairs. The collected data were compiled, coded and stored safely and analyzed afterward. The data analysis process was performed with help of SPSS 16 version and WHO Anthro3.2.2 version. For assess the associated factors we used SPSS and applied correlation. For measure the deviation of weight-for-height, weight-for-age, length/heightfor-age, BMI-for-age and arm circumference-for-age there was used WHO Anthro and applied Z-score valves.

\section{Results}

Despite the heterogeneous society of Kapikvastu district 93.33\% respondents were Hindu and remaining were Buddhists and Muslims. Similarly, more than three-fourth respondents

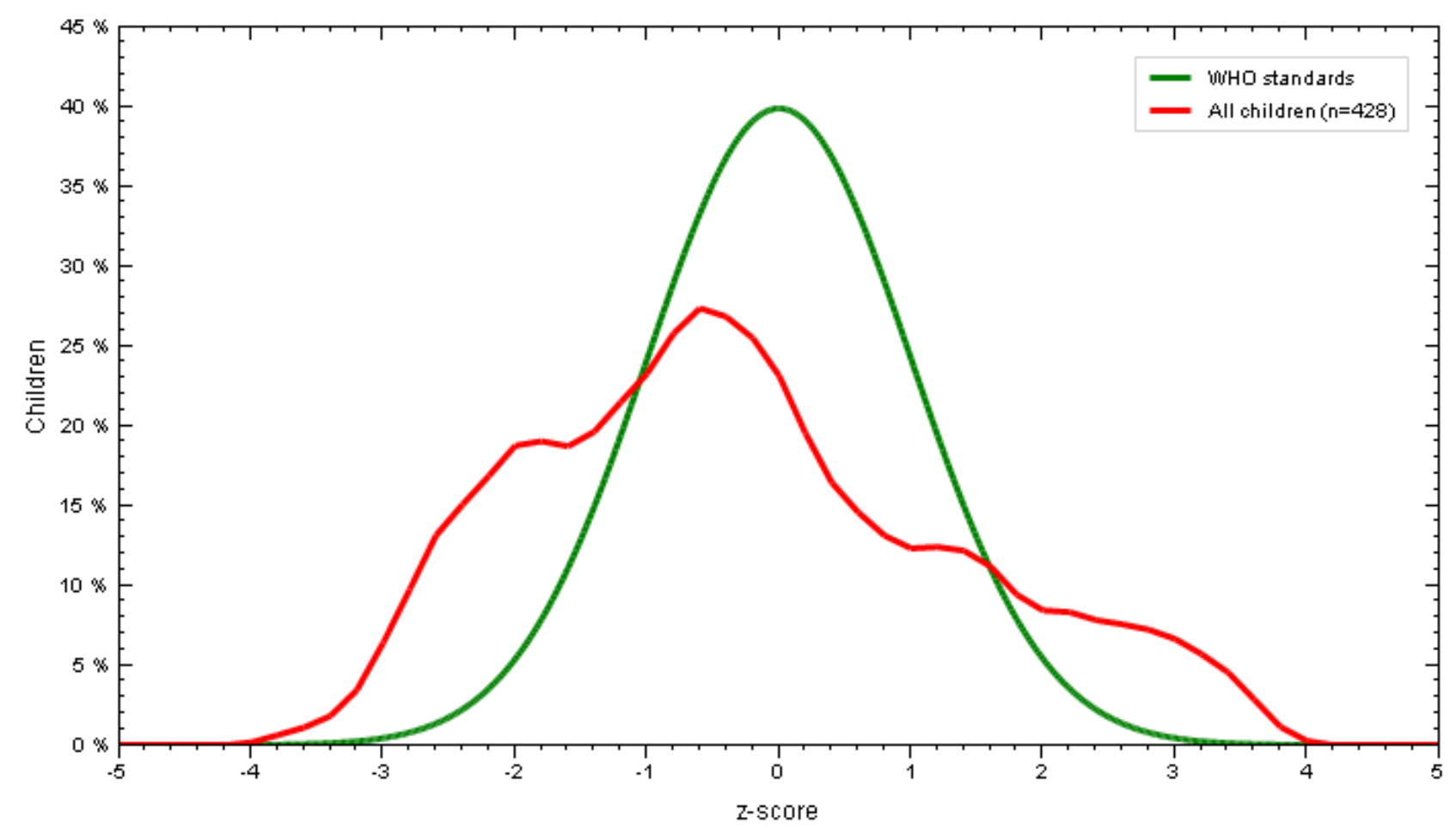

Figure 1: Weight -for-height. Regarding the weight-for-height, 23\% children were below the -1 SD (Z- scores), $16 \%$ children were below the -2 $\mathrm{SD}$ and $6 \%$ children were below the $-3 \mathrm{SD}$. The relation between weight and height of the children was statistically significant $(\mathrm{r}=0.788$ and $\mathrm{p}<0.05)$. 


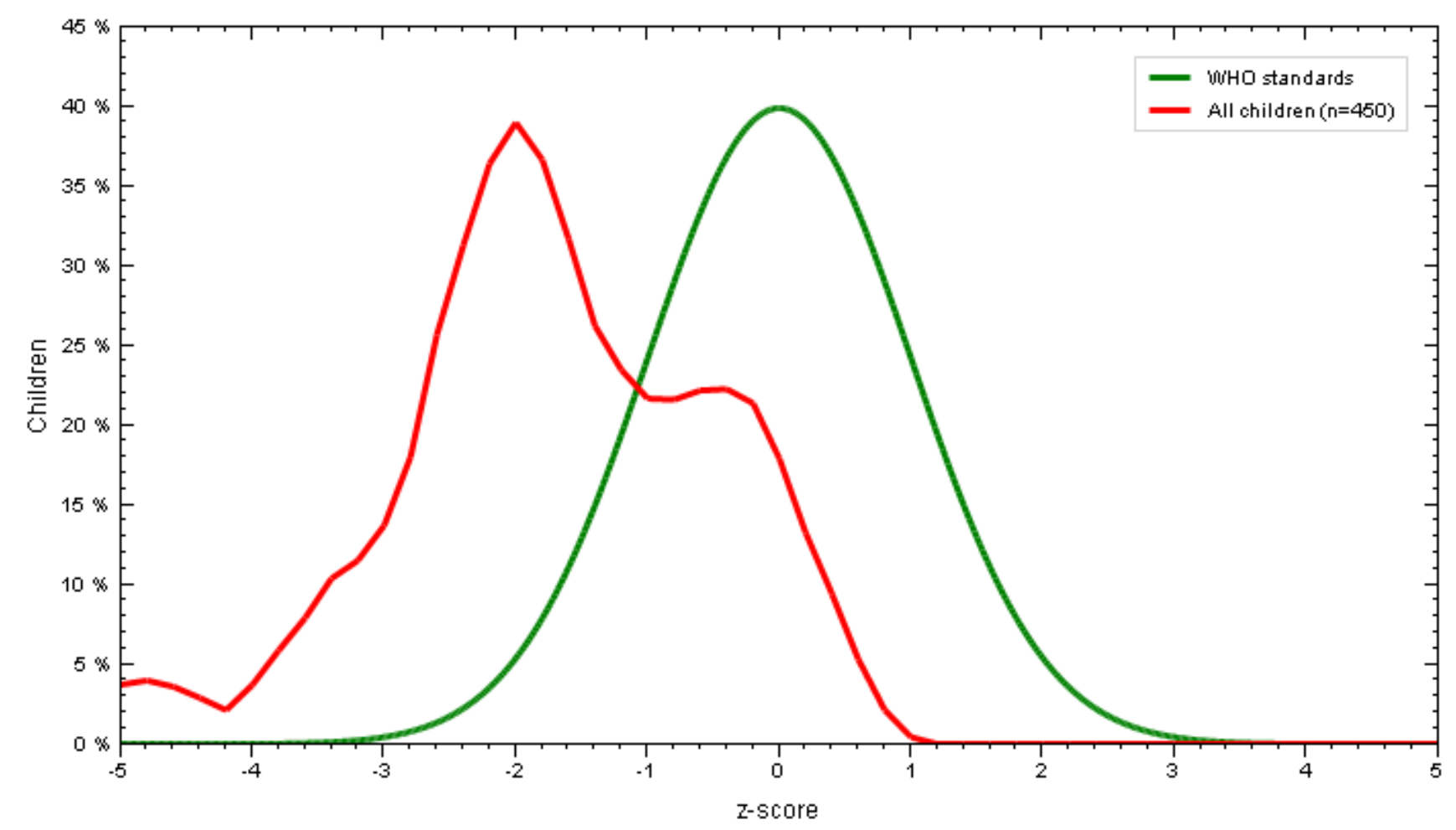

Figure 2: Weight -for -age. By assessing the health status of children on the basis of weight-for-age; $23.5 \%$ children were below the -1 SD $31.5 \%$ children were below the -2 SD and $11.5 \%$ children were -3 SD. Correlation between weight and age is statistically significant $(r=0.737$ and $p<0.05)$.

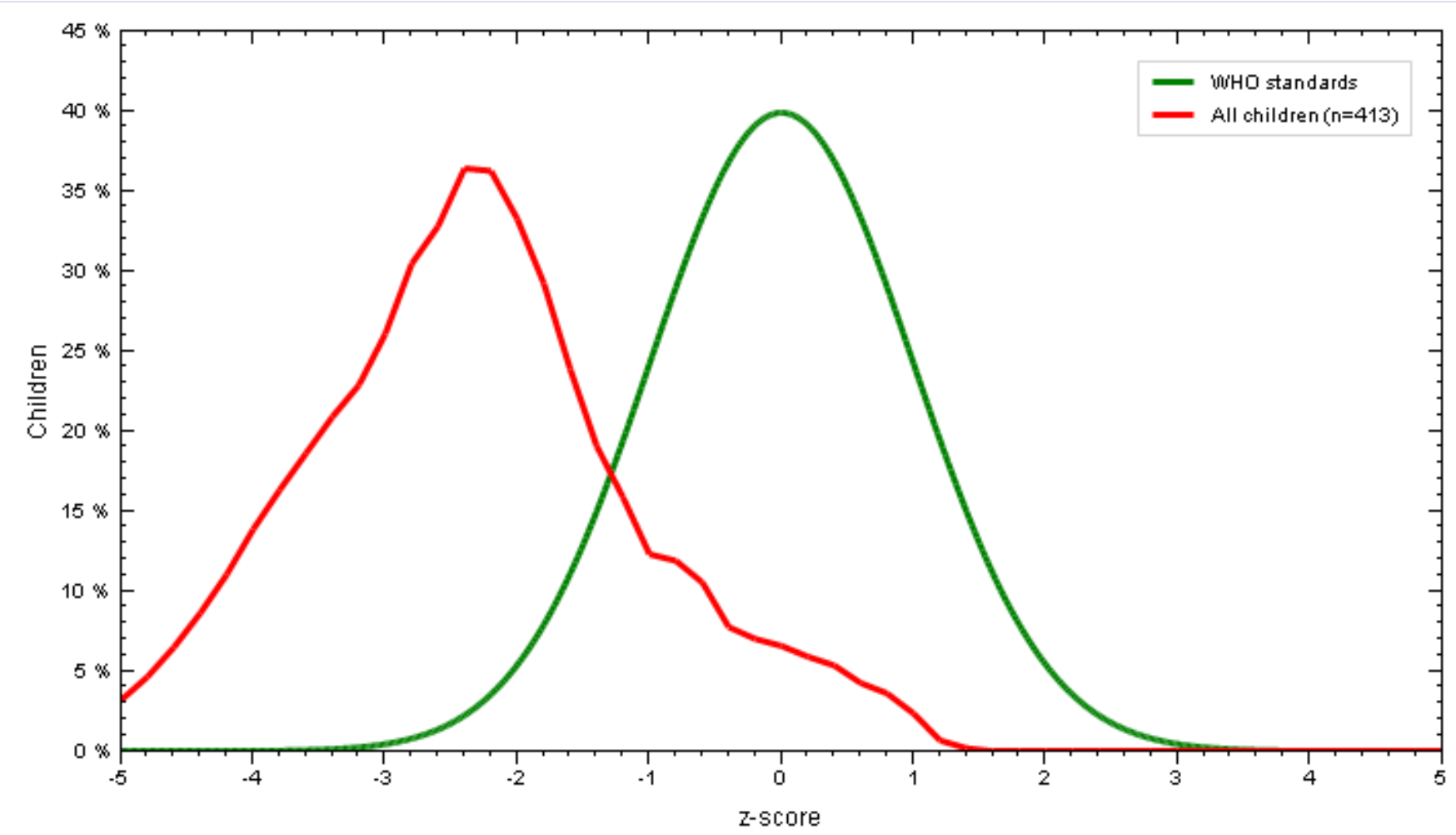

Figure 3: Height -for-age. According to the height-for-age, $11.8 \%$ were below the -1 SD, $30.8 \%$ were below -2 SD and $25 \%$ were below the -3 SD. The height and age of the children had statistically significant relation ( $r=0.775$ and $p<0.05)$. 


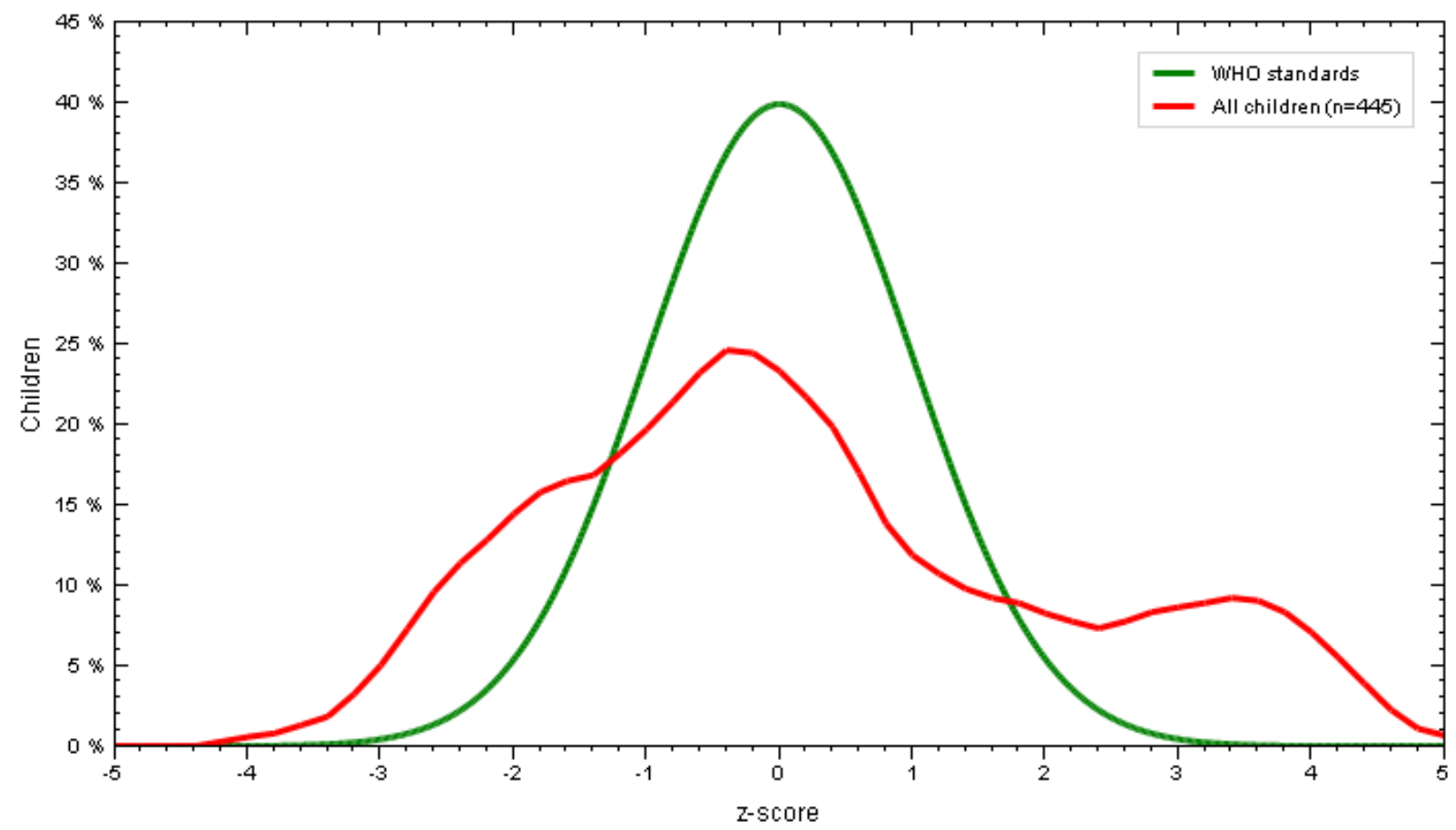

Figure 4: BMI-for -age. By assessing the BMI-for-age, 19.5\% children were below -1SD, 14.5\% were below -2SD while 5\% children were below -3SD.

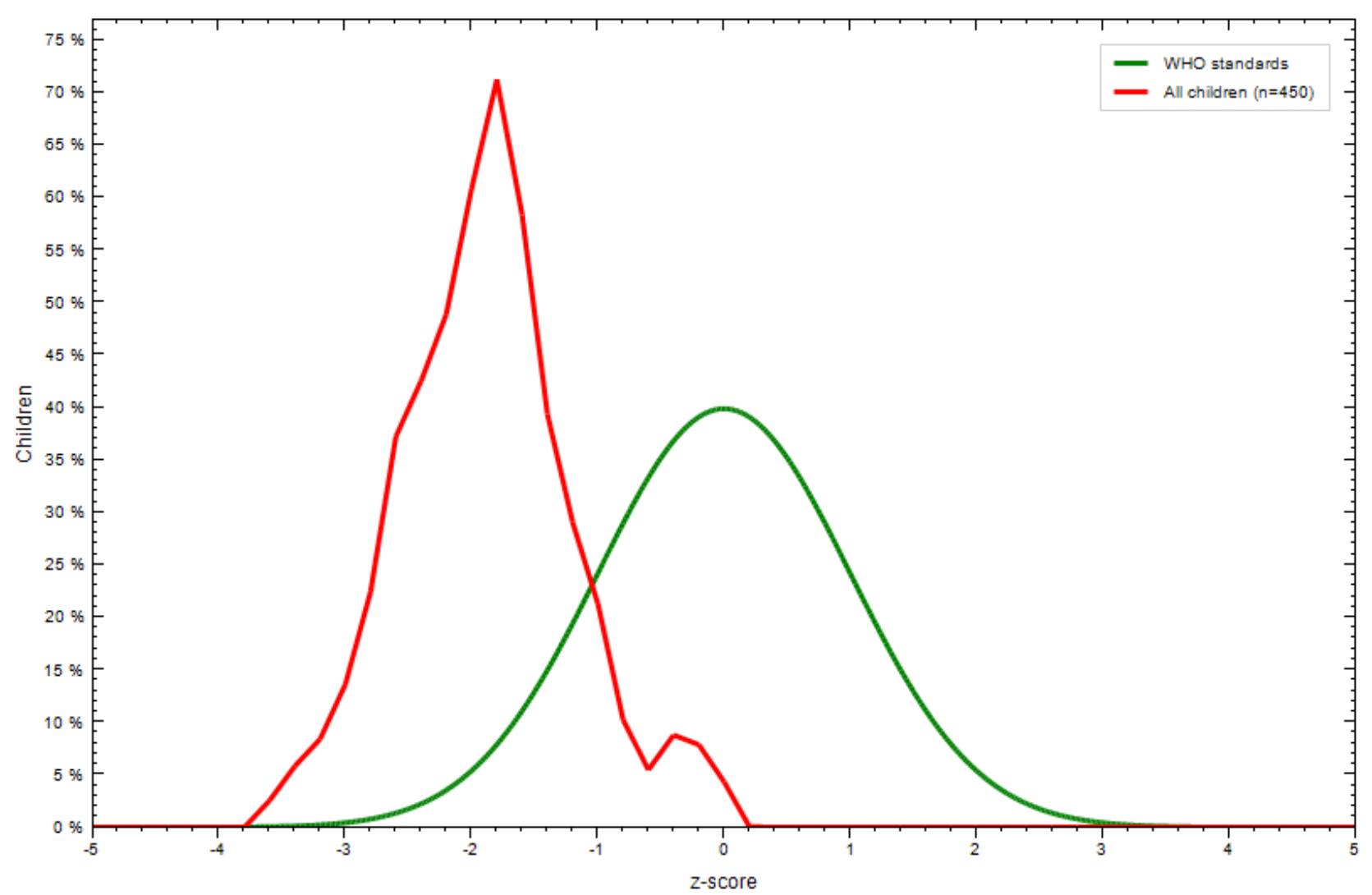

Figure 5: Mid upper arm circumference (MUAC)-for-age. Correlation between MUAC measurement and age of child is significant at the 0.01 level (2-tailed). By assessing the Mid Upper Arm Circumference (MUAC)-for-age, 21.5\% children were below -1 SD, 60\% were below -2 SD and 15\% were below $-3 \mathrm{SD}$.

Citation: Bhandari TR, Chhetri M (2013) Nutritional Status of Under Five Year Children and Factors Associated in Kapilvastu District, 
were from Dalits (so called non-touchable caste), disadvantage groups and tribal castes.

In study areas, nearly two-thirds households economic was depended on day-labor, agriculture and foreign employment. The highest $30.22 \%$ households can bear their necessities up to six month by their annual income and the mean and standard deviation of the annual affordability of the income were 7.91 and 2.94 months respectively. There is practice of joint as well as nuclear family whereas more than half of the respondents live in nuclear family. The mean, mode and standard deviation of the family size were $6.38,4$ and 2.48 correspondingly.

\section{Discussion}

For assessing the nutritional status and factors associated, 450 under five year children were selected from Kapilvatu district of Nepal. Respondents were from different backgrounds i.e. religions, castes and geographical areas, socio-economic status. The major findings of the study are discussed here briefly.

For rapid assessment of nutritional status of children, single indicator weight-for-height is used in emergencies and resources constraint situation. As per the weight-for-height assessment children below -2SD and -3SD are considered seriously and critically malnourished respectively and they need immediate interventions [8].

Based on height-for-age assessment $11.8 \%$ were below the -1 SD, $30.8 \%$ were below -2 SD and $25 \%$ were below the -3 SD [6,7]. Similar findings were from Kathmandu valley where prevalence of stunting and underweight (<-2 SD) was similar in both boys ( $45.57 \%$ stunting and $52.46 \%$ underweight) and girls $(43.42 \%$ stunting and $46.09 \%$ underweight) [9].

Study further endorses that children who lived under moderate to severe malnutrition condition in their early child hood were suffered from high episodes of diarrhoeal diseases and acute respiratory tract infections. 29\% of Zimbabwean children aged 3-60 months were short in relation to their age when compared with an international reference population. Analysis of the height-for-age measurement showed a positive correlation between malnutrition and rural residence, birth status (infants in multiple births are more likely to be malnourished), lower birth weight, shorter birth interval, and suffering from diarrhea [10] Nutritional interventions are needed to moderate malnutrition for preventing server condition i.e. progression to marasmus or kwashiorkor [11]. Findings of this study and above studies are seen similar as well as comparable.

Weight-for-age measurement revealed the protective importance of maternal education, urban residence, low episodes of diarrheal and respiratory diseases, normal birth weight, birth order up to two and better breast feeding status. Similarly, the weight-for-height scales revealed duration of breast feeding and early starting of supplementary food as the sole significant variables. Thus, it appears that birth order, birth weight, diarrheal disease episodes, duration of breast feeding and rural residency were most significant determinants of malnutrition among under five children. It is concluded that a multi-disciplinary approach is needed to combat the socioeconomic factors which are pushing the under five year children towards malnutrition [12]. In Nghean Vietnam, 31.8\% were underweight, $44.3 \%$ were stunting and $11.9 \%$ were wasting. Region of residence, the mother's level of education and occupation, household size, number of children in the family, weight at birth and duration of exclusive breastfeeding were found to be significantly related to malnutrition [13]. Similar variables of this study i.e. height, weight and MUAC measurements are significantly related with nutritional status of under five year children.

Nutrition is an important determinant of immunological status. Under-nutrition can make poorer immune competence and increase chances of susceptibility and make vulnerable to infections. The immediate causes of malnutrition and high mortality of under five year children are inadequate dietary intake and frequent episodes of diarrhoeal and respiratory diseases. Not only severe malnutrition even mild to moderate malnutrition also increases of various infections and risk of dying in childhood [14]. Immunization status, exclusive breast feeding and health care seeking were found statistically significant with nutritional status of the children in Kapilvastu district.

In far western district Kanchapur Nepal 21.8\% of under five year children were severely stunted, $25 \%$ moderately stunted, 9.1 $\%$ were moderately and $1.4 \%$ were severely wasted, $28 \%$ were moderately underweight and $9.7 \%$ were severely underweight [15]. Findings of the above study and this study are closely comparable each other. BMI-for-age, $19.5 \%$ children were below -1SD, $14.5 \%$ children were below -2 SD and $5 \%$ children were below -3SD. Similarly, the correlation between MUAC and age is significant at the 0.01 level (2-tailed). As regards the MUAC- forage, in the study $21.5 \%$ children were below -1 SD, $60 \%$ were below -2 SD and 15\% were below -3 SD.

\section{Conclusion}

Nearly two-thirds children were found malnourished in Kapilvastu district of Nepal. By considering weight, height, age, BMI and MUCA measurements of malnourished children nearly half of them were found below the -2SD ( $\mathrm{Z}$ score) and one-fourths below -3SD ( $\mathrm{Z}$ score) which is regarded as serious condition and children need immediate intervention. Better socio-economic status, mother's age between 20-35 years, birth order up to second, birth spacing more than two years between two pregnancies, recommended exclusive breast feeding, early recommended supplementary foods, complete immunization and timely care seeking behaviors had positive effect on children nutrition status and also these variables were found statistically significant.

\section{Acknowledgements}

We would like to express our authentic gratefulness to all respondents who had provided valuable information and kind cooperation in our research project. Similarly, we extend our sincere gratitude to School of Health and Allied Sciences, Faculty of Science and Technology, Pokhara University, Nepal for the financial support. 


\section{References}

1. Collins S, Dent N, Binns P, Bahwere P, Sadler K, et al. (2006) Management of severe acute malnutrition in children. Lancet 368(9551): 1992-2000.

2. http://www.who.int/gho/child_health

3. Nazni P, Pradheepa S, Hasan A (2010) Effects of weaning biscuits on the nutritional profile and the cognitive development in preschool children. Italian Journal of Pediatrics 36(1): 1-6.

4. Government of Nepal. National Census-2001(2001) Kathmandu: Central Bureau of Statistics, Nepal, Thapathali.

5. Ministry of Health and Population Nepal and New ERA, and Macro International Inc. (2006) Nepal Demographic and Health Survey 2006. Kathmandu, Nepal: Ministry of Health and Population, New ERA, and ICF International, Calverton, Maryland.

6. Department of Health Services (2011) Annual Report 2009/210. Ministry of Health and Population, Nepal.

7. Department of Health Services (2012) Annual Report 2009/210 Ministry of Health and Population, Nepal.

8. World Health Organization (1995) The management of nutritional emergencies in large populations. ( $2^{\text {nd }}$ edn), World Health Organization, Geneva, Switzerland.

9. Ghosh A, Adhikari P, Chowdhury SD, Ghosh T (2009) Prevalence of under-nutrition in Nepalese children. Ann Hum Biol 36(1): 38-45.

10. Madzingira N (1995) Malnutrition in children under five in Zimbabwe: effect of socioeconomic factors and disease. Soc Biol 42(3-4): 239-246.

11. Broeck VDJ, Eeckels R, Vuylsteke J (1993) Influence of nutritional status on child mortality in rural Zaire. Lancet 341(8859): 1491-1495.

12. Wamani H, Astrom AN, Peterson S, Tumwine JK, Tylleskar T (2006) Predictors of poor anthropometric status among children under 2 years of age in rural Uganda. Public Health Nutrition 9(3): 320-326.

13. Hien NN, Kam S (2008) Nutritional status and the characteristics related to malnutrition in ochildren under-five years of age in Nghean, Vietnam. J Prev Med Public Health 41(4): 232-240.

14. Urban J (1997) Success Factor in Community Based Nutrition Oriented Programme and Project. Atlas of South Asian Children and Women, UNICEF, ROSA UNICEF, Asia.

15. Onta S (2003) Knowledge, practice and coverage final survey in Kanchapur district Nepal. Care Nepal, Child Survival Project, Nepal. 